\title{
VIOLÊNCIA ESCOLAR, PROFESSORES e ALUNOS PROTAGONISTAS DE UMA TRISTE HISTÓRIA ${ }^{1}$.
}

\author{
Maria do Carmo de Lima
}

\section{RESUMO}

O objetivo do presente estudo é analisar a estrutura construída da violência dentro do âmbito escolar, entendendo suas causas e consequência para que, assim, possa-se indicar medidas de atuação tanto por parte dos professores, da escola, das famílias e da sociedade como um todo. Pode-se concluir, portanto, que deve-se sempre entender a dinâmica da violência como algo social que pode gerar ou ser gerada na escola mas que deve ser sempre tratada com grande cuidado justamente pela possibilidade do adoecimento psíquico que pode causa aos professores que ali a vivencia.

Palavras-chave: educação, violência, bullying.

\begin{abstract}
The aim of the present study is to analyze the built structure of violence within the school environment, understanding its causes and consequences, so that it is possible to indicate measures of action by teachers, school, family and society as a whole. All It can be concluded, therefore, that the dynamics of violence must always be understood as something social that can or can be generated at school but that should always be treated with great care precisely because of the possibility of psychic illness that can cause teachers there the experience.
\end{abstract}

Keywords: education, violence, bullying.

\section{RESUMEN}

O objetivo do presente estudo é analisar a estrutura construída da violência dentro do âmbito escolar, entendendo suas causas e consequência for que, assim, possa-se indica medidas de atuação tanto por parte dos professores, da escola, das famílias y da sociedade como um que hacer. Pode-se concluir, portanto, que deve-se sempre entender a dinâmica da violência como algo social que pode gerar ou ser gerada na escola mas que deve ser sempre tratada con grande cuidado justamente pela posibilidade do adoecimento psíquico que pode causa aos professores que ali una vivencia

Palabras clave: educación, violencia, bullying

\footnotetext{
${ }^{1}$ Artigo extraído da Dissertação de Mestrado em Ciências da Educação "Violência Escolar..." Faculdad Interamericana de Ciencias Sociales-FICS. Orientador Prof. Dr. Marco Aurélio Borges, Vitória/ES, julho/2020.

2 Acadêmica do Curso de Pós-Graduação em Ciências da Educação: Violências, escola, comunidade, família, revisão bibliográfica, Faculdad Interamericana de Ciencias Sociales-FIC; advogada, especialista em Direito Público, Direito Médico, professora regente, marialimaadv@gmail.com
} 


\section{1- INTRODUÇÃO}

O presente artigo cientifico possui como finalidade abordar a temática da violência presente nas relações entre alunos e professores no espaço escolar. A escolha desta temática se deu em razão do crescente número de casos noticiados pela mídia e aqueles narrados por professores, por alunos, bem contabilizando situações de professores e de alunos acerca de situações de violência na relação aluno/professor.

Assim, o trabalho visa discorrer sobre violência escolar contra alunos e professores tal qual se apresenta no contexto do mundo globalizado, dentre eles o acesso à internet e proliferação de informações e suas consequências no âmbito escolar, trazendo uma bibliografia atual da violência nas escolas.

A legislação brasileira conta com diversos dispositivos legais que podem ser buscados para melhor orientação às famílias às escolas, aos professores e aos alunos destacando-se a Constituição Federal de 1988, Lei de Diretrizes e Bases da Educação Nacional (Lei n 9.394/96), Lei n. ${ }^{\circ}$ 8.069/90 (Estatuto da Criança e do Adolescente), Lei n 10.406 , de 10 de janeiro de 2002 (Código Civil Brasileiro (BRASIL, 2002).

Mencionam Marcolino et al (2018, p. 2) "o bullying surge como uma modalidade da violência na escola e distingue-se a esta, pois diz respeito à afirmação de poder interpessoal por meio da agressão/violência", demonstrando, portanto, não ser apenas a violência pela violência, mas uma relação de luta pelo poder, pela superioridade.

Os Tribunais estão tratando o assunto como "bullying" mesmo considerando que a figura do professor foi a envolvida, não se tratando apenas de relação entre alunos para que se caracterize a figura jurídica que vem sendo combatida nos ambientes escolares.

Bullying é a prática de atos violentos, intencionais e repetidos, contra uma pessoa indefesa, que podem causar danos físicos e psicológicos às vítimas. O termo surgiu a partir do inglês bully, que significa a tirano, brigão ou valentão, na tradução para o português.

Para a justiça brasileira, o bullying está enquadrado em infrações previstas no Código Penal, como injúria, difamação e lesão corporal.

Etimologicamente, o termo é formado a partir da junção das palavras "cyber", palavra de origem inglesa e que é associada a todo o tipo de comunicação virtual usando 
mídias digitais, como a internet, e bullying que é o ato de intimidar ou humilhar uma pessoa. O cyberbullying é mais fácil para os agressores, porque podem fazê-lo de forma anônima nas diversas redes sociais, através de e-mails ou de torpedos com conteúdos ofensivos e caluniosos. (https://www.significados.com.br/cyberbulliyng/).

Bullying também pode ser praticado por professores ou outros profissionais que têm um controle de supervisão sobre os alunos. Nesse caso é definido como um padrão de conduta, enraizado num diferencial de poder, que ameaça, fere, humilha, induz medo ou provoca considerável stress emocional nos alunos. Aqui se incluem comportamentos que qualquer pessoa razoável reconheceria como tendo um risco significativo de prejudicar os alunos.

Especificamente o legislador brasileiro cuidou também de legislar acerca de violência praticada sem motivação evidente por indivíduo ou grupo de pessoas contra uma ou mais pessoas através da Lei $n^{\circ} 13.185$, de 06 de novembro de 2015 institui o Programa de Combate à Intimidação Sistemática (Bullying). Registra-se ainda, a Lei Estadual n. ${ }^{\circ} 22.623$, de 27 de julho de 2017 que estabelece medidas para conter atos de violência contra educadores e servidores da Secretaria de Educação do Estado de Minas Gerais.

Pontuado esse arcabouço legislativo tem-se, portanto, a base legal para se orientar escolas, escolares, famílias, docentes, otimizar suas relações, enfrentar a violência nas escolas, prestigiando a participação dos alunos, de suas famílias e da sociedade, viabilizar maior integração da escola com a comunidade escolar, prestigiando a participação efetiva no debate acerca dos problemas relacionados à escola e em sua solução.

Nas práticas pedagógicas possíveis de se utilizar, se encontram a realização de palestras, debates e encontros sempre com a participação ativa de alunos, professores, comunidade escolar e família dos alunos. Os meios atuais de comunicação também propiciam a possibilidade de registrar e divulgar eletronicamente ocorrência agressão ou ameaça, nas escolas e nas secretarias de educação.

Ainda assim, a problemática proposta para o presente estudo encontra-se na seguinte indagação: a violência escolar existe entre os próprios alunos e entre alunos e professores, seria ela o resultado de problemas socioculturais mais complexos ou apenas o reflexo da falta da formação de professores para lidar com tal fenômeno? 
Para que tal problemática possa ser respondida, o objetivo do presente estudo é analisar a estrutura construída da violência dentro do âmbito escolar, entendendo suas causas e consequência para que, assim, possa-se indicar medidas de atuação tanto por parte dos professores, da escola, das famílias e da sociedade como um todo.

O objetivo principal deste artigo é uma reflexão sobre o tema violência no contexto escolar procurando entender as várias formas em que ela se apresenta e como reflete nos indivíduos dessa sociedade.

Quanto aos objetivos específicos apresentam-se as várias formas de violência, tais como real, simbólica, bullying, ciberbullying, praticados por alunos ou professores dentro e fora da comunidade escolar; identificar essas várias formas de violência no ambiente escolar; apontar possíveis caminhos e consequências desse problema que se apresenta no mundo com fundamento nas percepções dos pesquisadores especialistas.

Justifica-se socialmente pelo fato de que atualmente a sociedade está imersa num contexto diverso de trocas interpessoais. De fato, a circulação facilitada na diversidade entre indivíduos com livre acesso à internet e outras decorrências da globalização, o que torna possível a construção de novas atitudes e valores que se compartilha de maneira fácil e rápida, por muitas vezes, sem uma reflexão mais aprofundada por professores e alunos.

Academicamente, justifica-se no momento que propõe reflexões dos textos legais aplicados aos direitos e deveres da escola, da família, dos professores e dos alunos, também da necessidade de envolver a família na comunidade escolar, a influência da formação e práticas de docentes, as políticas públicas educacionais sobre violência escolar, os reflexos das relações sociais dos alunos no contex to escolar.

Após, tratou-se da formação dos professores e como isso influencia no trato com a violência escolar e como o Judiciário tem apontado estratégias para pacificação de conflitos, a exemplo da Mediação. Por fim, serão apresentadas as considerações finais.

\section{2-DELIMITAÇÕES METODOLÓGICAS.}

De acordo com Carvalho (2000), o conhecimento científico é caracterizado como uma procura das possíveis causas de um acontecimento. Assim, segundo o autor, em uma pesquisa existe a busca pela compreensão e/ou explicação da realidade que a entorna, a partir da apresentação dos fatores que determinam a existência deste acontecimento. 
$\mathrm{O}$ autor ainda coloca que

[...] Não basta saber que o fermento faz o bolo crescer. É necessário, sobretudo, caracterizar o que, na constituição do fermento, produz o efeito que é o crescimento do bolo. Uma vez obtido este conhecimento, deve-se garantir sua aplicabilidade, isto é, sua validade em outras situações (Carvalho, 2000, p. 11).

Esse artigo de cunho bibliográfico, exploratório e descritivo, consiste de uma pesquisa bibliográfica porque será realizada a partir de levantamentos de referências teóricas já escritas, analisadas e publicadas por meios escritos em papel ou eletrônicos (livros, artigos científicos, leis, por meio físicos, isto é, impressos ou páginas da web).

Utilizando-se a revisão crítica de literatura, o primeiro passo tomado para o presente estudo foi o levantamento bibliográfico acerca da temática proposta com estudos documentais sobre violência escolar com ênfase nas relações entre alunos e professores; estudos realizados em livros, artigos e períodos apontam sobre a violência escolar, com enfoque nas relações alunos e professores.

Utilizou-se os indexadores: Google Acadêmico, Scielo e as bases de teses e dissertações da USP, Unicamp e outras universidades públicas brasileiras. Como termos de procura, utilizou-se: bullying, escola, violência, violência simbólica, violência escolar, formação de professores, formação do professor e papel da gestão escolar. Como termo conectivo utilizou-se "and" para que o número de resultado fosse mais restrito e de acordo com o tema.

Após o levantamento os devidos cortes foram realizados para que o número de trabalhos a serem utilizados fosse reduzido. Assim, utilizou-se os seguintes critérios: relação com a temática, data de publicação e importância do autor para com a área pesquisada (caso de Freira, Foucault e Bourdieu, por exemplo), tendo em vista o vasto embasamento necessário para o presente estudo.

Realizada a produção textual, diversas apresentações à orientação foram realizadas, correções feitas e, por fim, culminou no presente estudo.

\section{3- CONSIDERAÇÕES ACERCA DA VIOLÊNCIA}

A violência pode ser considerada como sendo um fenômeno multifacetado, tendo diversas definições conforme o escopo delineado para se entender tal fenômeno. Pode-se, 
também, observar a violência dento de diversos âmbitos e, desse modo, a mesma acabará assumindo características específicas a que forem observadas.

A violência tratada neste trabalho perpassa pela conceituação de ser a incapacidade de expressar simbolicamente o que se deseja, recorrendo-se a ações destrutivas, que possuem o potencial de desorganizar o processo de ensino-aprendizagem e enfraquece as relações sociais no interior da escola (Sposito, 1998), contempla atos de vandalismo, indisciplina, mas também atos cotidianos de desrespeito e incivilidades.

No caso do presente estudo, a violência aqui considerada é aquela desenvolvida dentro do ambiente escolar, sendo consequência ou início da violência exposta na sociedade que pode ser observada atualmente, como coloca Tiradentes (2015).

Pode-se dizer, portanto, segundo Sacramento e Rezende (2006) que a violência é uma questão social e, portanto, não é objeto próprio de nenhum setor específico seja para estudo, seja para ação efetiva de políticas públicas.

Interessantemente dizer que existe, também, a violência política dos sistemas sociais que ocorre sob tutela econômica do que alguns chamam hipercapitalismo, ostentando aspectos ao mesmo tempo diferentes e paralelos, como aqueles que dispõem, de um lado, os Estados Unidos ou a Europa e, de outro, a China, a Índia ou o Japão.

As grandes tradições comuns que fundam o que era até hoje a humanidade entendem as relações humanas como ligadas à cultura e à violência endêmica dessa relação. Ela ganhou múltiplos aspectos no curso dos séculos precedentes, mas hoje, globalmente mediatizada, sustentada ou reivindicada em termos de guerras de ingerência, de regulação, de política de civilização, essa violência, cultura da força, sob todas suas formas, é claramente o tronco comum da humanidade globalizada (PAIN, 2010, pp. 7-8).

Desse modo, observa-se que a globalização tem, segundo o autor da citação acima, essa grande virtude de forçar igualmente encontros, trocas, intercâmbios entre civilizações, com ou sem o consentimento das pessoas.

No lugar da análise e dos efeitos da demanda põe-se uma formatação, uma construção de comportamentos de consumo, alimentares, sexuais, artísticos e fantasísticos em todos os domínios da sociedade, da relação, em ligação estreita com o que esse hipercapitalismo produziu, um hiperindividualismo assentado sobre suas posses 
materiais e mentais. $\mathrm{O}$ imaginário está no comando. E é assim que a violência começa a ganhar forma de maneira ampliada.

Segundo Elias (2001), essa diferenciação das funções sociais é, no entanto, apenas a primeira das transformações que deu origem ao processo civilizatório. Junto com essa divisão de funções, segundo o mesmo autor, ocorre a reorganização do tecido social.

De acordo com o referido autor, quando

[...] a divisão de funções é baixa, os órgãos centrais de sociedades de certo tamanho são relativamente instáveis e propensos à desintegração. E que também através de pressões específicas de configurações humanas, as tendências centrífugas, os mecanismos da feudalização lentamente vão sendo neutralizados e, passo a passo, uma organização central mais estável, uma monopolização mais firme da força física, são estabelecidos (ELIAS, 2001, p. 97).

A escola, neste turno, porta-se como instrumento para manipulação desse modo de "aprender", impulsionando os alunos a serem meros reprodutores de conhecimento, desprezando suas peculiaridades e especificidades. Tal procedimento é perfeitamente adequado à ótica que perfaz o plano escolar no que tange à perpetuação da forma de pensar da classe dominante, tornando totalmente dispensável a interação de educandos de classes populares no que se perquire as atividades do campo.

A violência pode se manifestar na forma de vários tipos de agressão, de incivilidade e de desrespeito, mas resulta de conceitos, preconceitos, práticas cotidianas, representações sociais inadequadas, problemas psicológicos e mesmo da própria ignorância (WITTER, 2010, p. 11).

Eric Debarbieux, afirma que: a maior parte dos autores que investigam o problema da violência escolar aceita uma definição ampla que inclui atos de delinquência não necessariamente passiveis de punição, ou que, de qualquer forma, passam despercebidos pelo sistema jurídico. (DEBARBIEUX, 2002, p.60)

A partir de Debarbieux, atos de delinquência praticados em ambiente escolar, previstos ou não como tais pelo sistema jurídico, são atos que poderiam ser caracterizados como violência escolar, variando de grau de intensidade e também do grau de intensidade de seus efeitos, merecendo a devida apuração no aspecto de quantificação para o para fins 
de reparação de eventuais danos. Para Debarbieux são espécies de violência escolar a violência patrimonial, violência simbólica, Também a violência contra professores.

Cláudia Regina de Oliveira leciona: sabe-se que as situações de penúria em que se encontram esses estudantes, a carência tanto emocional quanto financeira, implicam no surgimento de diversas reações como a inveja e a revolta. Essas emoções influenciam os comportamentos intersubjetivos predispondo-os a atitudes de teor violento. (Oliveira, 2000, pp. 87-88)

Como indica Miriam Abramovay já que, para ela, esta forma de violência também pode ocorrer:

Quando as escolas impõem conteúdos destituídos de interesse e de significado para a vida dos alunos; ou quando os professores se recusam a proporcionar explicações suficientes, abandonando os estudantes à sua própria sorte, desvalorizandoos com palavras e atitudes de desmerecimento. (ABRAMOVAY: 2002, p.335)

Não se pode negar que, desde que ocorra no âmbito educacional, não importa quem cometa, é violência escolar. Faz importante, portanto, tratar a violência no âmbito escolar a partir de seus autores sejam eles alunos, professores e outros profissionais da educação ou mesmo outros agentes da comunidade escolar.

Porém, no intuito de manter o enfoque do presente estudo, será tratada a violência entre alunos e entre alunos e professores.

Em seu estudo Giordani et al (2017) percebeu, nos relatos de alunos participantes que a violência entre eles é multifacetada, indicando ter origem externa à escola, na maioria dos casos, interferindo na rotina escolar. De acordo com os autores a violência entre os alunos vai do uso de xingamentos e presença de preconceitos as agressões tanto orais quanto físicas quando o conflito não encontra outro meio de manifestação.

Neste sentido os autores colocam que

[...] compreendendo-se a violência estabelecida nas relações sociais na escola, torna-se evidente a importância de ações da direção da escola e dos professores e funcionários no sentido de auxiliar os alunos envolvidos a reconhecerem e solucionarem as situações de conflito (GIORDANI et al 2017, p. 105). 
Vale ressaltar ainda, o que os autores da citação ainda mencionam que as manifestações de violência serão específicas de cada escola, ou seja, por serem reflexos da comunidade na qual estão inseridas serão diferenciadas mas a essência violenta será a mesma.

\section{- O PROFESSOR E SUA ATUAÇÃO COM A VIOLÊNCIA ESCOLAR}

Segundo Witter (2010), muitas vezes, por uma formação falha, falta ao professor competência na administração de uma sala de aula ou em controlar estratégias didáticas e, assim, o comportamento e produtividade dos alunos faz com que esse docente grite, esbraveje e até mesmo agrida verbalmente o aluno ou seus valores.

Tudo isso acaba por reduzir a autoestima do aluno. Forma-se, assim, um círculo vicioso do qual o aluno-vítima não consegue escapar. Os colegas somam esforços com a professora, o fundo do poço fica sem fim. Pobre criança! Esses são apenas arquétipos do cotidiano da escola. Pior é o ato de violência no qual a criança é abandonada, dentro de sua própria sala, sem qualquer empenho para que não fique para trás. Tratam-se de exemplos do que ocorre nas salas de aula, que não chegam às manchetes de jornais e raramente a direção está atenta a tais aspectos (WITTER, 2010, p. 15).

As sociedades, segundo Perrenoud (1999), transformam-se constantemente devido às novas formas de tecnologias, informações, comunicações, relações cotidianas etc. As desigualdades, segundo Faria e Costa (2011), acabam por se deslocarem, se agravarem e se recriam em novos territórios.

Perrenoud (1999) afirma que é preciso ancorar a prática reflexiva sobre uma base de competências profissionais:

1. organizar e animar as situações de aprendizagem; 2. Gerir o progresso das aprendizagens; 3. Conceber e fazer evoluir os dispositivos de diferenciação; 4.envolver os alunos nas suas aprendizagens e no seu trabalho; 5. Trabalhar em equipe; 6. Participar da gestão da escola; 7. Informar e envolver os pais; 8. Servir-se 2860 de novas tecnologias; 9. Enfrentar os deveres e dilemas éticos da profissão; 10. Gerir sua própria formação contínua (PERRENOUD, 1999, p.9).

Assim, a formação continuada do professor possibilita sua melhor atuação em sala de aula na condução dos episódios das várias formas de bullying. 


\section{- O FENÔMENO BULLYING}

De acordo com Vechi (2013) pode-se afirmar que o bullying é

um ato de violência física ou verbal, que pode causar consequências que vão desde o âmbito emocional até consequências na aprendizagem, devido ao fato de ocorrer principalmente com crianças e adolescentes dentro do contexto escolar (VECHI, 2013, p. 38).

É de suma importância, no entanto, lembrar que para que um comportamento se caracterize como bullying ele precisa ser repetitivo, ou seja, é preciso, segundo Vechi (2013), diferenciar um desentendimento ou briga momentânea de algo que vem se repetindo constantemente.

Carvalho (2007) refere que as primeiras investigações sobre bullying foram realizadas na Suécia nos anos 1970, e a partir daí o interesse se generalizou para os outros países escandinavos e outras regiões da Europa e Estados Unidos.

Sposito (2001), nos lembra que a partir de 1980 ocorrem às primeiras pesquisas sobre violência escolar no Brasil, quando o tom predominante era de expor as constantes depredações e atos de vandalismo. Constata-se que a partir dos anos 1990, a violência escolar passa a ser preponderante nas interações dos grupos de alunos, aumentando a complexidade de análise destes fenômenos. Neste sentido, é possível evidenciar, por exemplo, a frequente existência de agressões verbais e ameaças.

Atualmente, segundo Zequinão et al (2016) profissionais de psicologia e educação consideram o bullying como sendo reflexo da violência social que ocorre na sociedade que se manifesta das formas variadas, crescendo em todos os segmentos e contextos humanos.

Além da violência explícita, há violências representadas por comportamentos cruéis, intimidadores e repetitivos contra uma mesma vítima. $\mathrm{O}$ bullying é um tipo de violência velada que gera e alimenta a violência, causando danos individuais e sociais significativos para os indivíduos. Ele é conhecido como um conjunto de comportamentos agressivos, que ocorrem sem motivação evidente, adotado por um ou mais alunos contra outro (a), causando dor, angústia e sofrimento dentro do âmbito escolar (ZEQUINÃO et al 2016, p.183). 
Como pode ser visto, o bullying sempre existiu, mas sempre foi tratado como brincadeiras, como algo que não necessitava de um olhar mais sério por parte dos professores ou outros profissionais ligados à educação.

\section{CYBERBULLYING}

Segundo Schreiber e Antunes (2017), o bullying que já era a expressão da violência da sociedade agora extrapola o ambiente escolar através das mídias sociais caracterizando o cyberbullying que, segundo os autores acima mencionados pode ser definido como sendo,

o uso de informações e de tecnologias de comunicação - como email, celular, aparelhos e programas de envio de mensagens instantâneas e sites pessoais - com o objetivo de difamar ou apoiar de forma deliberada comportamentos, seja de indivíduo ou grupo, que firam de alguma forma outros tantos (SCHREIBER e ANTUNES, 2017, p. 110).

Não se pode esquecer que, no cyberbullying, segundo Wendt e Lisboa (2014), há a transcendência do espaço e do tempo tanto para a vitimação quanto para a agressão isso porque o número de espectadores por ser indeterminado e multiplicar-se numa dimensão absurda que não é visto no bullying. Schreiber e Antunes (2017) colocam, no entanto, que existem as semelhanças entre os dois tipos de violência que não podem ser deixadas de lado.

\section{BULLYING NA VISÃO DAS LEIS BRASILEIRAS}

Para Lopes Neto (2005, p. 165):

(...) três documentos legais que formam a base de entendimento com relação ao desenvolvimento e educação de crianças e adolescentes: A Constituição da República Federativa do Brasil, o Estatuto da Criança e do adolescente e a Convenção sobre os Direitos da Criança da Organização das Nações Unidas. Em todos esses documentos, estão previstos os direitos ao respeito e à dignidade, sendo a educação entendida como um meio de prover o pleno desenvolvimento da pessoa e seu preparo para a cidadania.

A Constituição da República Federativa do Brasil, o Estatuto da Criança e do adolescente e a Convenção sobre os Direitos da Criança da Organização das Nações Unidas, garantem o direito ao desenvolvimento pleno da criança e do adolescente. 
A partir da Carta de 1988 as leis infraconstitucionais que tratam da educação, tanto o Estatuto da Criança e do Adolescente (Lei no 8.069/90) quanto a e Lei de Diretrizes e Bases da Educação (Lei $n^{\circ}$ 9.394/96) trazem a fórmula mais adequada para o combate à violência nas escolas: o envolvimento dos alunos, de suas famílias e da comunidade, com sua integração cada vez maior ao ambiente escolar e participação efetiva no debate acerca dos problemas relacionados à escola e em sua solução.

\section{- RESULTADOS e DISCUSSÃO}

Nesta sessão serão apresentados os resultados advindos da busca bibliográfica, as publicações selecionadas e a principal temática que cada uma delas trata para que, por fim, pudesse ser utilizada no presente estudo como embasamento teórico.

Ensinar na conjuntura atual da sociedade se constitui numa tarefa estressante. A instituição escolar não se encarrega apenas da escolarização, mas também da educação moral e de valores já esquecidos pelas famílias ora justificada pela falta de tempo oriunda das exigências da sociedade capitalista, ora pela impaciência e descaso em relação a crianças e adolescentes.

Essa informação acaba por sugestionar que são necessárias pesquisas mais avançadas que comparem grupos com e sem situações de risco, para verificar se essa condição social pode ter influenciado nessas diferenças entre os sexos, ou então se, de fato, essa mudança de comportamento observada nos últimos anos é uma tendência para a igualdade entre os sexos, inclusive nos papéis de participação no bullying.

\section{CONSIDERAÇÕES FINAIS}

A violência sofrida na infância e juventude exerce impactos bastante perversos sobre as habilidades socioemocionais, o aprendizado, os resultados do mercado de trabalho e o engajamento em comportamentos de risco na vida adulta. Os impactos da violência escolar são ainda mais preocupantes, uma vez que esta atinge principalmente estudantes com maiores desvantagens socioeconômicas.

Esta é exatamente a contribuição deste artigo, que traz evidências para o contexto de países em desenvolvimento sobre a influência de diferentes fatores associados a este fenômeno. 
Os resultados mostram que os crimes contra o patrimônio estão basicamente relacionados à dificuldade de gestão da escola e às condições socioeconômicas do entorno.

Compreendendo-se a violência estabelecida nas relações sociais na escola, tornase evidente a importância de ações da direção da escola e dos professores e funcionários no sentido de auxiliar os alunos envolvidos a reconhecerem e solucionarem as situações de conflito. Entretanto, também os professores relataram carecer de formação e apoio para que consigam atuar de forma efetiva na prevenção e resoluções.

Pode-se concluir, portanto, que deve-se sempre entender a dinâmica da violência como algo social que pode gerar ou ser gerada na escola mas que deve ser sempre tratada com grande cuidado justamente pela possibilidade do adoecimento psíquico que pode causa aos professores e alunos que ali a vivenciam.

\section{REFERÊNCIAS}

ABRAMOVAY, M.; RUA, M. G. Violências nas escolas. Brasília, DF: UNESCO, 2002. BOURDIEU, P. Escritos de educação. 2a Ed. Petrópolis: Editora Vozes, 1998.

BRASIL. Lei n ${ }^{\circ}$. 8.069, de 13 de julho de 1990. Dispões sobre o Estatuto da Criança e do Adolescente e dá outras providências. Estatuto da Criança e do Adolescente. Brasília, DF, 1990.

BRASIL, Constituição da República Federativa. 5 de outubro de 1988. Disponível em: http://www.planalto.gov.br/ccivil_03/constituicao/constitui\%C3\%A7ao.htm.

CARVALHO, M. P. Violência nas escolas: o "bullying" e a indisciplina. Observatório da Infância. Agosto, 2007. Disponível em: http://www.observatoriodainfancia.com.br/article.php3?id_article=233. Acesso em: 06/08/2019.

CONSTITUIÇÃO DA REPÚBLICA FEDERATIVA DO BRASIL DE 1988. Disponível em http//planalto.gov.br/ccivil_03/constituição/constitu\%7ao.htm 4 Acesso $\mathrm{em}$ $\underline{07 / 08 / 2019)}$

CHARLOT, Bernard. A violência na escola: como sociólogos franceses abordam essa questão. Tradução de: Sônia Taborda. Revista Sociologias. Porto Alegre, RS. No 8 jul/dez 2002. 
DEBARBIEUX, Eric. A violência na escola francesa: 30 anos de construção social do objeto (1967- 1997). Educação e Pesquisa, São Paulo, v. 27, n. 1, p.163-193, 2001 Promotor de Justiça no Estado do Paraná

ELIAS, N. O processo civilizador: formação do Estado e Civilização. V.2. Rio de Janeiro: Zahar, 2001.

FARIA, A.; COSTA, J. Violência escolar: o fenômeno bullying e a formação docente. (2011). Disponível em: https://educere.bruc.com.br/CD2011/pdf/5135_2715.pdf. Acesso em: 23/07/2019.

Lei $\mathrm{n}^{\circ}$. 10.406, de 10 de janeiro de 2002. Institui o Código Civil. Brasília, DF, 2002.

Disponível em: 〈http://planalto.gov.br/CCIVIL/leis/2002/L10406.ttm >. Acesso em: 19

JULHO DE 2019

Lei de Diretrizes e Bases da Educação Nacional - Lei nº 9.394 (20/12/1996)

LOPES NETO, A. A. Bullying - comportamento agressivo entre estudantes. Jornal de Pediatria. Vol. 81, N5 (Supl), 2005 Disponível em: http://www.observatoriodainfancia.com.br/IMG/pdf/doc-154.pdf. Acesso em; 13/07/2015.

MARCOLINO, E. et al. Bullying: prevalência e fatores associados à vitimização e à agressão no cotidiano escolar. (2018). Disponível em: http://www.scielo.br/pdf/tce/v27n1/0104-0707-tce-27-01-e5500016.pdf. Acesso em: 22/05/2019.

MEC tem medidas para enfrentar ações de violência nas escolas Disponivel em http://portal.mec.gov.br/ultimas-noticias/211-218175739/47721-especialistas-indicamformas-de-combate-a-atos-de-intimidacao Acesso em 06/08/2019

https://meuartigo.brasilescola.uol.com.br/administracao/gestor-na-mediacao-conflitosescolas-publicas.htm

PAIN, JACQUES. Os desafios da escola em face da violência e da globalização: submeterse ou resistir? In: SILVA, Joyce Mary Adam de Paula. e SALLES, Leila Maria Ferreira (Orgs). Jovens, violência e escola: um desafio contemporâneo [online]. São Paulo: Editora UNESP; São Paulo: Cultura Acadêmica, 2010.

PERRENOUD, P. Formar Professores em contextos sociais em mudança: Prática reflexiva e prática crítica. Universidade de Genebra, 1999. 
Sacramento Violências: lembrando alguns conceitos e Tartari Lívia; Rezende Morgado Manuel

https://www.redalyc.org/pdf/1150/115013462009.pdf acesso em 16 de jun.2020

SCHREIBER, F.; ANTUNES, M. Cyberbullying: do virtual ao psicológico. Bol. Acad. Paulista de Psicologia, São Paulo, Brasil - V. 35, no 88, p. 109-125, 2015.

SPÓSITO, Marília Pontes. Um breve balanço da pesquisa sobre violência escolar no Brasil. Revista Educação e Pesquisa, São Paulo, v. 27, n.1, p. 24-39, 2002.

TIRADENTES, A. Violência simbólica no contexto escolar: discriminação, inclusão e o direito à educação. Revista Eletrônica do Curso de Direito - PUC Minas Serro - n. 12 - Agosto / Dez. 2015.

VECHI, A. Bullying o perigo nas escolas. Revista de Educação. v.15, n.19, 2012, p. $37-52$.

WENDT, G.; LISBOA, C. Compreendendo o Fenômeno do Cyberbullying. Trends in Psychology / Temas em Psicologia - 2014, Vol. 22, nº 1, 39-54.

ZEQUINÃO, M. et al. Bullying escolar: um fenômeno multifacetado. Educ. Pesqui., São Paulo, v. 42, n. 1, p. 181-198, jan./mar. 2016.

ZEQUINÃO, M. et al. Bullying escolar: um fenômeno multifacetado. Educ. Pesqui., São Paulo, v. 42, n. 1, p. 181-198, jan./mar. 2016. 